\title{
General practitioners' management of hypertension in elderly patients
}

\author{
M D Fotherby, G D Harper, J F Potter
}

\begin{abstract}
Objective-To assess general practitioners' attitudes to the diagnosis and management of hypertension in elderly patients.

Design - Postal questionnaire to all general practitioners in Leicestershire.

Results -360 of 451 general practitioners (80\%) responded. $81 \%$ (292) reported rechecking an initially high blood pressure on two or three occasions before starting treatment, $56 \%(202)$ measured sitting blood pressure only, and just $28 \%(100)$ took sitting and standing levels. $36 \%$ (128) had no upper age limit for starting anti-hypertensive treatment; of the $58 \%$ (206) who did, the median was 80 (range 7099) years. Blood pressure levels reported for starting treatment in patients aged 70-79 years were $180(150$ 240)/106 (90-120) $\mathrm{mm} \mathrm{Hg.} \mathrm{34 \%} \mathrm{of} \mathrm{general} \mathrm{practition-}$ ers (121) would not treat isolated systolic hypertension. The most popular first line treatment for an elderly hypertensive patient was a thiazide diuretic; only $17 \%$ of general practitioners $(61)$ initially tried non-pharmacological methods. $34 \%$ (122) would continue anti-hypertensive treatment unchanged in the period immediately after stroke.

Conclusions-The variation among general practitioners in the criteria for the measurement, diagnosis, and treatment of hypertension in elderly patients emphasises the need for clear management guidelines in this age group.
\end{abstract}

\section{Introduction}

Pharmacological treatment of hypertension in patients aged up to 80 years has been shown to reduce cardiac and cerebrovascular mortality, ${ }^{12}$ though clear guidelines on the management of raised blood pressure in this age group have been lacking until very recently. The British Hypertension Society's management document on treating mild hypertension made little mention of age related changes in the assessment and treatment of elderly patients with hypertension except that "more frequent, careful monitoring of elderly patients and a more gradual reduction of blood pressure may be necessary." 3 The World Health Organisation and International Society of Hypertension suggested that patients aged over 70 years in good general health be treated in the same way as younger patients, with the caveat that there was as yet no evidence of benefit in treating people aged over $80 .{ }^{4}$ Many important issues concerning hypertension in elderly patients have not been answered by the British Hypertension Society or WHO guidelines, such as the management of isolated systolic hypertension or hypertension after stroke. Hospital physicians tend to use different criteria for starting treatment in older patients than in middle aged and younger subjects. ${ }^{5}$ As most elderly hypertensive patients are treated by their general practitioners, however, this does not reflect how most such patients are managed.

To establish the range of views and current treatment practices in the management of hypertension in elderly patients, we conducted a survey covering current issues relevant to this age group among local general practitioners.

\section{Methods}

A postal questionnaire was sent to all 451 Leicestershire general practitioners between February and April 1991 with a stamped addressed envelope for return. A covering letter explained the object of the questionnaire and that it referred to an asymptomatic healthy person unless otherwise stated. Returned forms were identified by a number specific for each general practitioner. Those not responding after six weeks received a second mailing; there was no further intervention if a reply was not received after a further six weeks. The questionnaire was divided into four sections covering measurement, age criteria and blood pressure levels for diagnosing and treating "hypertension," treatment choice, and effect of stroke on blood pressure management - a total of 11 questions.

Results were entered into a personal computer and analysis was carried out with the Minitab statistical package. Results are expressed as median values with ranges or as the number and percentage of those who responded to each question.

\section{Results}

A total of $366(81 \%)$ of questionnaires were returned; six were blank, leaving $360(80 \%)$ suitable for analysis.

\section{BLOOD PRESSURE MEASUREMENT}

General practitioners were asked on how many visits they would check blood pressure before starting treatment in a 70 year old with an initial blood pressure reading of 199/115 $\mathrm{mm} \mathrm{Hg}$ and no evidence of end organ damage. A total of $292(81 \%)$ reported that they would check the blood pressure on two or three subsequent visits before starting treatment (table I). Most $(230 ; 64 \%)$ general practitioners would take two blood pressure readings on each occasion, although

TABLE I - Treatment decision for 70 year old man with no evidence of end organ damage and blood pressure of $199 / 115 \mathrm{~mm} \mathrm{Hg}$

\begin{tabular}{lc}
\hline Number of visits & $\begin{array}{c}\text { No (\%) of } \\
\text { general practitioners }\end{array}$ \\
\hline Treat immediately & $11(3)$ \\
Check blood pressure on: & \\
1 Further visit & $50(14)$ \\
2 Further visits & $202(56)$ \\
3 Further visits & $90(25)$ \\
Decide not to treat & $7(2)$ \\
\hline
\end{tabular}

Correspondence to:

Dr Fotherby. 
$28 \%$ (99) would take only one measurement and $8 \%$ (28) more than two. Over half the respondents (200; $56 \%$ ) would take the readings with the patient in the sitting position only and $11 \%(41)$ in the supine position only. A third (120) would include a standing blood pressure measurement, although only $28 \%$ (100) reported taking sitting and standing readings.

INFLUENCE OF AGE ON TREATMENT OF BLOOD PRESSURE

For a patient with a confirmed blood pressure of $199 /$ $115 \mathrm{~mm} \mathrm{Hg}, 36 \%$ of respondents (130) had no age limit for initiating treatment; of the $58 \%$ (209) who did, the median age limit was 80 (range 70-99) years. There was considerable variation in the systolic and diastolic blood pressure values at which general practitioners would start treatment in each age group, with levels tending to increase with age (table II).

TABLE II-Number (\%) of general practitioners prepared to star treatment of patient with blood pressure $199 / 115 \mathrm{~mm} \mathrm{Hg}$

\begin{tabular}{lcccc}
\hline & & & \multicolumn{2}{c}{$\begin{array}{c}\text { Median (range) blood pressure } \\
(\mathrm{mm} \mathrm{Hg}) \text { for starting treatment }\end{array}$} \\
\cline { 4 - 5 } $\begin{array}{l}\text { Patients } \\
\text { age (years) }\end{array}$ & Treating & $\begin{array}{c}\text { Don't } \\
\text { know }\end{array}$ & Systolic & Diastolic \\
\hline $65-69$ & $353(98)$ & 0 & $175(140-220)$ & $100(90-120)$ \\
$70-79$ & $346(96)$ & $4(1)$ & $180(150-240)$ & $106(90-120)$ \\
$80-89$ & $223(62)$ & $35(10)$ & $190(150-240)$ & $110(90-135)$ \\
$\geqslant 90$ & $112(31)$ & $33(2)$ & $195(150-240)$ & $110(90-135)$ \\
\hline
\end{tabular}

Isolated systolic hypertension (systolic pressure $>160 \mathrm{~mm} \mathrm{Hg}$ and diastolic pressure $<90 \mathrm{~mm} \mathrm{Hg}$ ) would not be treated at all by $34 \%$ of general practitioners (121), while only $16 \%$ (57) would treat if the systolic pressure was $<200 \mathrm{~mm} \mathrm{Hg}$ (table III).

TABLE III - Number (percentage) of general practitioners who would treat isolated systolic hypertension

\begin{tabular}{lc}
\hline Systolic blood pressure $(\mathrm{mm} \mathrm{Hg})^{\star}$ & No (\%) who would treat \\
\hline $160-179$ & $4(1)$ \\
$180-199$ & $53(15)$ \\
$200-220$ & $104(29)$ \\
$>220$ & $68(19)$ \\
Would not treat & $121(34)$ \\
Don't know & $10(3)$ \\
\hline
\end{tabular}

${ }^{\star}$ Diastolic pressure $<90 \mathrm{~mm} \mathrm{Hg}$

\section{TREATMENT PREFERENCES}

General practitioners were asked their first choice of treatment for a 70 year old hypertensive patient without evidence of target organ damage and also what treatment they rarely or never used. Most $(223 ; 62 \%)$ started treatment with a thiazide diuretic; $10 \%(40)$ would use a calcium channel blocker and $6 \%$ (22) a $\beta$ adrenoceptor antagonist. Over $30 \%$ of general practitioners would not use methyldopa (136) or an $\alpha$ blocker (107) as the initial treatment for hypertension. However, just $17 \%$ (62) used non-pharmacological treatment as a first line measure; in those who did, reduction of weight $(313 ; 90 \%)$ and of alcohol intake $(205 ; 59 \%)$ were the commonest methods employed; $37 \%$ (129) tried an exercise programme, 36\% (125) dietary sodium restriction, and $<2 \%$ (5) increasing dietary potassium intake.

\section{BLOOD PRESSURE MANAGEMENT AFTER STROKE}

For a patient receiving antihypertensive treatment who has a stroke and is seen by a general practitioner within 48 hours, a third (122) of respondents would continue antihypertensive treatment unchanged, 5\% (18) would stop treatment altogether, and 59\% (212) would adjust treatment according to the patient's blood pressure levels. After a stroke in a patient with a "raised blood pressure" who had not previously received antihypertensive treatment, the period before starting treatment was considered, ranged from one day to 26 weeks, with a median of 14 days; only $2 \%$ of general practitioners (7) would not institute treatment and $20 \%(70)$ were unsure how long to wait. The median systolic and diastolic pressures for starting treatment in a 70 year old after a stroke were $180(140$ 220) $\mathrm{mm} \mathrm{Hg}$ and 105 (90-120) $\mathrm{mm} \mathrm{Hg}$, similar values to those given for treating hypertension in a patient with no evidence of end organ damage.

\section{Discussion}

As general practitioners treat most elderly hypertensive patients, their style of practice in managing raised blood pressure in this age group is therefore of great importance, although it has undergone virtually no previous assessment. Our questionnaire attempted to elicit general practitioners' actual practice, rather than what they thought they should do. From the design of the study, however, we have no independent way of validating how closely the responses represent actual clinical practice. The response to this survey was good compared with other surveys of similar type conducted in hospital based settings. ${ }^{6}$ Although $20 \%$ of general practitioners did not reply to the questionnaire there was no obvious systematic bias-replies were received from at least one partner for all practices and it is unlikely that the answers from non-responders would have significantly altered the findings.

A wide range of responses to most of the questions was found, suggesting differing criteria for both diagnosing and treating hypertension in this age group, although most general practitioners would seem to be in accord with the British Hypertension Society guidelines. ${ }^{3}$ That these differences exist is perhaps not surprising since there are few official guidelines owing to a lack of information on many issues. The survey results were obtained just before the publication of three treatment trials relevant to older hypertensive patients; systolic hypertension in elderly patients (SHEP), ${ }^{7}$ the Swedish trial in old patients with hypertension, ${ }^{8}$ and the Medical Research Council trial of treatment of hypertension in older adults, ${ }^{9}$ and before the proposed guidelines on management of elderly patients with sustained hypertension. ${ }^{10}$

\section{BLOOD PRESSURE READINGS BEFORE START OF} TREATMENT

How often blood pressure is measured will depend to some extent on the readings obtained; however, it is known that initially high levels tend to fall with repeated measurements, preferably taken on several visits. The British Hypertension Society's guidelines suggest taking six to eight readings over three to four months before considering drug treatment for mild hypertension, and the WHO/ISH guidelines ${ }^{4}$ suggest at least two measurements on four separate occasions before instituting treatment. Most general practitioners surveyed seem to take two readings at three visits, although a sizable minority would take fewer readings on fewer occasions. Patterson, by examining patient records, found only $45 \%$ of patients had had at least three blood pressure readings taken before a diagnosis of hypertension was made,${ }^{11}$ a finding in keeping with that reported by Smith and Clayton. ${ }^{12}$ The 1988 survey of British hypertension specialists found that the minimum number of blood pressure measurements taken before drug treatment for mild hypertension was started was three taken by $56 \%$ of respondents, four by $17 \%$, and five or more readings by $20 \%$ - figures similar to those reported in the present survey. Less than a third of general practitioners reported taking a standing blood pressure, although this is recommended in elderly patients in view of the high prevalence of postural hypotension $(10-24 \%)$ in this age group. ${ }^{1314}$ Standing blood pressure levels have also 
been suggested as a guide to treatment if found to be significantly lower than sitting or supine blood pressure readings. ${ }^{15}$

AGE LIMITS

The median age limit for initiating antihypertensive treatment was 80 years, in agreement with evidence available at the time of the survey; however, $36 \%$ of respondents reported having no age limit and $31 \%$ would start treatment in patients over 90 years old at a median blood pressure of $195 / 110 \mathrm{~mm} \mathrm{Hg}$. More recent trials have suggested possible benefits of reducing blood pressure in those aged 80-85, although beyond this age evidence is still lacking. Results from the hypertension specialists' survey suggested $40 \%$ would be prepared to start treatment in patients over 80 at an average blood pressure of $200 / 110 \mathrm{~mm} \mathrm{Hg}$, findings in close agreement with those of the general practitioners we surveyed.

Isolated systolic hypertension would not be treated by one third of respondents, and most of the remainder would require a systolic pressure of $200 \mathrm{~mm} \mathrm{Hg}$ or greater before starting treatment. This practice may change now that the results of the SHEP trial are available, showing benefit from treating systolic pressures of $160 \mathrm{~mm} \mathrm{Hg}$ or greater.

\section{TREATMENTS USED}

Although the effectiveness of non-pharmacological measures is recognised in reducing blood pressure levels in patients with mild to moderate hypertension, ${ }^{16}{ }^{17}$ only a small minority of general practitioners reported initially using such treatment. This may partly be explained by the limited evidence of efficacy in elderly hypertensive patients. Weight reduction and reduction of alcohol intake were the most frequently used methods, with little emphasis placed on salt restriction or increasing dietary intake of potassium. Thiazide diuretics, recommended as a first line antihypertensive agent by the British Hypertension Society, were the most popular pharmacological treatment, with very few general practitioners using $\beta$ blockers as first choice. It has recently been suggested that $\beta$ blockers cannot now be considered the treatment of choice in elderly hypertensive patients, ${ }^{10}$ but they may be of benefit in those who also have a history of angina, previous myocardial infarction, or certain dysrrhythmias.

Despite the good evidence for the primary prevention of stroke by antihypertensive treatment in elderly patients there is little convincing evidence that such treatment prevents stroke recurring in this age group ${ }^{18} 19$ though this may be because of the design of previous studies. It is therefore not surprising that little information is available on which to base guidelines for hypotensive treatment after stroke in elderly patients, though there are may case reports of such treatment precipitating stroke. ${ }^{2021}$ Blood pressure tends to rise acutely after a stroke, settling within one to two weeks. ${ }^{22}$ As cerebral autoregulation is impaired in the early post-stroke ${ }^{23}$ period aggressive hypotensive treatment should be avoided in most cases and may not be required at all in a large number of elderly stroke patients. Most general practitioners in this survey reported using similar criteria for diagnosing and initiating treatment after a stroke as they did in hypertensive patients who had not had a stroke.

\section{CONCLUSIONS}

Although there was good general agreement in some aspects of the management of elderly hypertensive patients between general practitioners and the British Hypertension Society's guidelines, there was a divergence of opinion on the blood pressure and age criteria for starting treatment. Evidence from studies published after this survey was conducted may provide the basis for more specific guidelines, for example, on the management of isolated systolic hypertension, although many issues, particularly the need for antihypertensive treatment after stroke, remain unresolved and require further studies. A follow up study will see if attitudes have changed in view of the recently published trials relating to the treatment of the elderly hypertensive patient.

We thank all general practitioners who participated in the study for their time and Dr C McGrother, department of community medicine, University of Leicester, for her help in compiling the questionnaire. MDF was funded by a grant from the British Heart Foundation.

1 Amery A, Birkenhäger W, Brixko P, Bulpitt C, Clement D, Deruyttere M et al. Mortality and morbidity results from the European Working Party on High Blood Pressure in the Elderly trial. Lancet 1985;i:1349-54.

2 Coope J, Warrender TS. Randomised trial of treatment of hypertension in elderly patients in primary care. $B M \mathcal{F} 1986 ; 293: 1145-51$.

3 British Hypertension Society Working Party. Treating mild hypertension. BMF 1989;298:294-8.

4 The Guidelines Sub-Committee. 1989 guidelines for the management of mild hypertension: memorandum from a WHO/ISH meeting. I Hyperten 1989;7:689-93.

5 Waller PC, McInnes GT, Reid JL. The policies for managing hypertensive patients: a survey of the opinions of British specialists. I Hum Hypertens 1990;4:509-15.

6 Smith WCS, Cromby IK, Campion PD, Knox GDE. Comparison of response rates to a postal questionnaire from a general practice and research unit. rates to a postal question

7 SHEP Co-operative Research Group. Prevention of stroke by antihypertensive drug treatment in older persons with isolated systolic hyper-
hy hypertensive drug treatment in older.
tension. FAMA 1991;265:3255-64.

8 Dahlof B, Lindholm LH, Hanson L, Schersten B, Ekbon T, Wester PO. Morbidity and mortality in the Swedish trial in old patients with hyperten sion (STOP-Hypertension). Lancet 1991;338:1281-5

9 Medical Research Council Working Party. MRC trial of treatment of hypertension in older adults: principal results. $B M \mathcal{F}$ 1992;304:405-12.

10 Beard K, Bulpitt C, Mascie-Taylor H, O'Malley K, Sever P, Webb S. Management of elderly patients with sustained hypertension. BMJ 1992 304:412-6.

1 Patterson HR. Criteria for the diagnosis of hypertension in general practice. $\mathcal{I} R$ Coll Gen Pract 1984;34:97-9.

12 Smith TD, Clayton D. Individual variation between general practitioners in labelling of hypertension. $B M \mathcal{F}$ 1990;300:74-5.

13 Caird FI, Andrews SR, Kennedy RD. Effects of posture on blood pressure in the elderly. Br Heart $\mathcal{f}$ 1973;35:527-30.

14 Mader SL, Josephson KR, Rubenstein LZ. The prevalence of postural hypotension among community-dwelling elderly. FAMA 1987;258:1511-2.

15 Bulpitt CJ. Definition, prevalence and incidence of hypertension in the elderly. In: Amery A, Staessen J, eds. Hypertension in the elderly. Amsterdam: Elsevier, 1989: 153-69. (Handbook of hypertension in the elderly, vol 12.)

161988 Joint National Committee. The 1988 report of the Joint National Committee on Detection, Evaluation and Treatment of High Blood Pressure. Arch Intern Med 1988;148:1023-38.

17 Koopman H, Spreeuwenberg C, Westerman RF, Donker AJ. Dietary treatment of patients with mild to moderate hypertension in a genera practice: a pilot intervention study. $\mathcal{F}$ Human Hypertens 1990;4:368-74.

18 Carter AB. Hypotensive therapy in stroke survivors. Lancet 1970;i:485-9.

9 Hypertension-Stroke Co-operative Study Group. Effect of antihypertensive treatment on stroke recurrence. FAMA 1974;229:409-18.

20 Britton $\mathrm{M}$, deFaire $\mathrm{V}$, Helmes $\mathrm{C}$. Hazards of therapy for excessive hypertension in acute stroke. Acta Med Scand 1980;207:253-7.

21 Standgaard S. Cerebral ischaemia caused by overzealous blood pressure lowering. Dan Med Bull 1987;34(suppl 1):5-7.

22 Wallace JD, Levy LL. Blood pressure after stroke. FAMA 1981;246:2177-80. 23 Meyer JS, Shimazu K, Fukuuchi Y, et al. Impaired neurogenic cerebrovascular control and dysautoregulation after stroke. Stroke 1973;4:169-86.

(Accepted 23 fuly 1992) 